\title{
Land Development and Pigouvian Taxes: The Case of Peatland
}

\section{Journal Article}

Author(s):

Goetz, Renan U.

Publication date:

1997

Permanent link:

https://doi.org/10.3929/ethz-b-000422469

Rights / license:

In Copyright - Non-Commercial Use Permitted

Originally published in:

American Journal of Agricultural Economics 79(1), https://doi.org/10.2307/1243956 


\title{
Land Development and Pigouvian Taxes: The Case of Peatland
}

\author{
Renan U. Goetz
}

In this paper the determination of an optimal Pigouvian tax for a competitive firm when a negative production externality is present concurrent with the development of land for production purposes is analyzed within a dynamic framework. Conditions are established for a convex social net return function where a Pigouvian tax is not required or where the imposition of a Pigouvian tax leads to the decision not to develop the land at all. In the case of a concave social net return function the Pigouvian tax is either a linear or a nonlinear tax on the private net returns.

Key words: dynamic optimization, land development, negative production externalities, Pigouvian taxes.

Pigouvian taxes can be considered as a firstbest environmental policy to achieve the socially desired ends if it is possible to measure the costs and benefits associated with the externality (Cropper and Oates). Apart from the question of whether or not Pigouvian taxes can be applied in reality, other issues related to Pigouvian taxes have been raised. Spulber analyzed the long-run efficiency properties of Pigouvian taxes and established an entry-exit condition for a long-run equilibrium that must be satisfied for an efficient outcome. Lee and Barnett proposed a second-best Pigouvian tax in light of imperfect competition in the presence of negative externalities. Baumol and Bradford showed that detrimental externalities tend to induce nonconvexity of the social production possibility set even if individual producers face a convex production possibility set. As a result, there may exist a multiplicity of local maxima, leaving the determi-

The author is a research associate in the Department of Agricul tural Economics, Swiss Federal Institute of Technology, Zürich, Switzerland and currently a visiting professor in the Department of Economics, University of Girona, Spain.

This paper was written while the author was visiting the Department of Agricultural and Resource Economics, University of California at Berkeley. An earlier version of this paper was presented at the VIII Congress of the European Association of Agricultural Economists, Edinburgh, 3-7 September 1996. Financial support from the Swiss National Science Foundation is gratefully acknowledged. The author thanks Michael Hanemann and two anonymous reviewers for their comments and helpful suggestions. nation of the global social maximum open. A similar result was obtained by Starrett where the failure of the second-order conditions arise from the nonconcavity of the function representing the firm's production function as it is affected by a negative externality.

In this paper the development of peatland for agricultural production where empirical evidence shows that the traditional assumption of strong concavity of the producer's net return function might not hold is characterized. In previous papers, the assumption of concavity is violated because producers of different goods are negatively affected by each other. By contrast, in this paper the nonconcavity of the net return function results from the opportunity of the producer to switch to production of more valuable goods through developing more of the essential and limiting factor, land quality. For the case of a convex social net return function, the optimal private and social outcome may be identically given by an upper boundary solution, and no Pigouvian tax is required. However, a Pigouvian tax may lead to the farmer's decision not to develop the land at all.

If the social and the private net return functions are concave, a linear Pigouvian tax on the private net return function induces the farmer to achieve the optimal social outcome. However, if the private net return function is convex, a nonlinear Pigouvian tax on the farmer's net returns is required to generate the optimal social outcome. 


\section{An Economic Model for the Development of} Peatland

The origin of peatland (organic soil) and its special properties in comparison with mineral soil have been described in detail by Goetz and Zilberman. They also described the key characteristics of the agricultural utilization of peatland, so we will be relatively brief with respect to these issues.

Under specific climatic and hydrologic conditions, plant residue does not completely decompose, which gives rise to the growth and deposit of peat. Peat is characterized by a high content of organic material and nutrients, and thus peatland is particularly interesting for agriculture. For example, peat contains on average more than $2.5 \%$ of nitrogen in the dry matter compared to $0.03 \%-0.3 \%$ for mineral soil (Kuntze, Roeschmann, and Schwerdtfeger). Growing crops on peatland requires developing the land beforehand by installing a drainage system. Inevitably, this will lead to the subsidence of the land due to an initial loss of volume and to a nearly constant rate of mineralization of the organic material (Schothorst). Segeberg has shown that the subsidence is directly proportional to the groundwater level and can be mathematically expressed as

$$
\dot{s}=-[f(t)+\gamma] g(t)
$$

where a dot over a variable denotes the operator $d / d t$ and $t$ time. The variable $s(t)$ represents the distance between the topsoil level and the drainage tubes (peat stock) (i.e., the amount of soil developed), $j$ the subsidence of the peatland, $f(t)$ an exponential distribution of time, $\gamma>0$ the constant mineralization rate, and $g(t)$ the distance between the topsoil level and the groundwater level. For a graphical illustration of the points of reference to measure the variables $s(t)$ and $g(t)$, see figure 1 . To simplify notation, the argument $t$ of $s, f, g$ and $z, \lambda, \phi_{i}, i$ $=1,2,3$ (to be introduced later), will be suppressed unless it is necessary for an unambiguous notation.

Different crops require for their optimal growth particular groundwater levels which can be set by the farmer by means of controlled drainage, either in the form of subirrigation or irrigation. Hence, the groundwater level determines the kind of crops that can be grown. A groundwater level of approximately $50 \mathrm{~cm}$ is optimal for growing grass. If the peatland is top-soil level

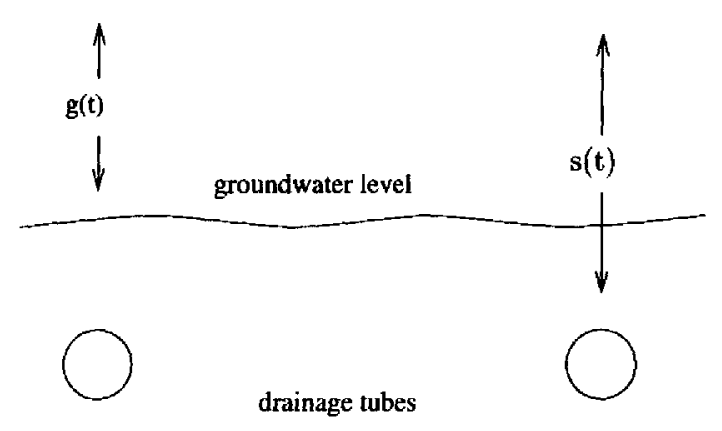

Figure 1. Cross section of drained peatland

drained up to $75 \mathrm{~cm}$, the farmer optimally can grow corn and various small grains, while draining the peatland to a depth of up to 100 $\mathrm{cm}$ enables the farmer optimally to grow vegetables (Poirée and Ollier, Maslov and Panov). The subsidence of peatland located in central western Europe from these farming practices ranges between $1-4 \mathrm{~cm}$ per year. The associated net return function $\pi(g)$, is a monotonically increasing function in $g$ with $\pi(0)=0$. The lower the groundwater level, chosen by the farmer, the more valuable the crops that can be grown at the expense of high subsidence rates of the soil. Depletion of the peat stock, however, reduces the future profitability of the land, and thus the farmer faces a trade-off between high immediate net returns for a shorter period of time versus lower net returns for a longer period of time.

As a case study for a particular area, the choice of the optimal intertemporal groundwater level for a net-return-maximizing farmer has been analyzed by Goetz and Zilberman. However, they did not consider the potential pollution of the groundwater and surface water with nitrogen $(\mathrm{N})$ in the form of nitrate as a result of the mineralization of the organic material. In Germany, where nearly the entire fen peatland is utilized for agricultural production (Göttlich and Kuntze), or in states or countries like Minnesota, Canada, or North Europe where large peatlands can be found, mineralization of the organic material is likely to affect the groundwater or surface water quality. ${ }^{1}$ Moreover, peatland often serves as a habitat for en-

\footnotetext{
In Finland and Sweden, for instance, $33.5 \%$ and $15.6 \%$ of the entire land respectively is covered with peat (Pfadenhauer et al.).
} 
dangered species of plants (Briemle). Therefore, its value as an environmental asset should be compared with the social benefits from the agricultural utilization of the peatland. Consequently, providing a benchmark for the decision as to whether $(a)$ to continue agricultural production on peatland or to restore its natural state by raising the groundwater level to the top soil level; or $(b)$ to convert intact peatland into productive agricultural land or to conserve it, should include negative production externalities.

The $\mathrm{N}$-mineralization for peat ranges from 300 to $1,200 \mathrm{~kg} \mathrm{~N}$ per hectare (ha) per $\mathrm{cm}$ peat loss. Even perennial crops like grassland are only able to assimilate $500 \mathrm{~kg} / \mathrm{ha}$ of $\mathrm{N}$ per year. Although some of the mineralized $\mathrm{N}$ is biologically denitrified and lost as gas in the form of $\mathrm{N}_{2} \mathrm{O}$ (Guthrie and Duxburg), a high share of the mineralized $\mathrm{N}$ is expected to leach into the groundwater or run into surface waters. Kuntze measured the $\mathrm{N}$ content of the groundwater recharge per hectare cultivated with agricultural crops. He found that the admissible $11.0 \mathrm{~kg} \mathrm{~N} /$ ha per $100 \mathrm{~mm}$ groundwater recharge for meeting $\mathrm{NO}_{3}$ regulations for drinking water in the European Community was not satisfied, reaching concentration levels up to six times above the standard.

Equation (1) shows that the groundwater level is proportional to the subsidence of the soil, and consequently as well to the release of nitrogen, denoted by $z$. Moreover, the release of nitrogen is monotonically increasing with $g$. As such, there exists a functional relationship $\beta z=$ $g, \beta>0$ and equation (1) and the net return function can be written as

$$
\dot{s}=-(f+\gamma) \beta z, \quad \pi(\beta z) .
$$

In the presence of a negative production externality given by the pollution of the groundwater and surface water, the costs and benefits of abating nitrate need to be considered. Hence, to ensure efficiency we assume that a social planner exists, and thus the social net return function is given by $\varphi(z)=\pi(\beta z)-[k(z)+d(z)]$, where $k(z)$ denotes the costs and $d(z)$ the benefits of abating the negative production externality. In line with the literature, it is proposed that $k+d$ is convex (see, for example, Baumol and Oates and Pearce). To simplify the notation we set $k(z)+d(z)=c(z)$ and refer to $c$ as social costs.

Now, we are able to state the optimal control problem for the social planner:

$$
\max _{z, t_{i}} \int_{0}^{t_{1}} e^{-\delta t} \varphi(z) d t
$$

subject to

$$
\begin{gathered}
\dot{s}=-(f+\gamma) \beta z, s(0) s_{0}, \\
z \in Z \equiv\left\{z: z=0 ; a \leq z \leq b ; z \leq \frac{s}{\beta}\right\}
\end{gathered}
$$

where $\delta>0$ presents the social discount rate, and $t_{1}$ denotes the end of the planning horizon. The maximum life span of the installed drainage system is given by $T$ and places an upper bound on $t_{1}$; therefore $t_{1} \in[0, T]$. As stated above, peatland can be utilized for agricultural production when $g$ is between 50 and $100 \mathrm{~cm}$, which corresponds to the values $a$ and $b$ for the control variable $z$. Moreover, as a physical necessity, $g$ must always be smaller than $s$, which yields the constraint $s-\beta z \geq 0$. The current value Hamiltonian is therefore given by $H=$ $\pi(\beta z)-c(z)-\lambda(f+\gamma) \beta z$, where $\lambda$ denotes the costate variable. Taking account of the constraints on the control variable $z$, we obtain the following Lagrangian: $L=H+\phi_{1}(z-a)+\phi_{2}(b$ $-z)+\phi_{3}(s-\beta z)$ where $\phi_{i}, i=1,2,3$, represents the Lagrange multipliers. A solution for problem $(P)$ has to satisfy the following necessary conditions which are stated in accordance with propositions 2.5 and 6.1 of Feichtinger and Hartl:

$$
\begin{aligned}
& L_{z}=\pi^{\prime}-c^{\prime}-\lambda(f+\gamma) \beta+\phi_{1}-\phi_{2}-\phi_{3} \beta=0 \\
& \dot{\lambda}=\delta \lambda-\phi_{3} \\
& \dot{s}=-(f+\gamma) \beta z, \quad s(0)=s_{0}
\end{aligned}
$$

where the subscript with respect to a variable denotes the corresponding partial derivative. Moreover, the optimal values of the control variable $z$ and the Lagrange multipliers have to satisfy the Kuhn-Tucker conditions: $L_{\phi_{i}} \geq 0, \phi_{i}$ $\geq 0$ and $\phi_{i} L_{\phi_{i}}=0$, for $i=1,2,3$. The constraint qualification will be satisfied due to the linearity of the restrictions in $z$ (Takayama). The transversality conditions are given by

$$
H\left(z^{*}, \lambda, t\right)\left(\begin{array}{l}
= \\
\geq
\end{array}\right) \quad \text { for }\left(\begin{array}{l}
t_{1}>T \\
t_{1}=T
\end{array}\right)
$$


(7)

$$
\begin{aligned}
& \lambda\left(t_{1}\right) \geq 0 \\
& s\left(t_{1}\right)-\beta a \geq 0 \\
& \lambda\left(t_{1}\right)\left[s\left(t_{1}\right)-\beta a\right]=0
\end{aligned}
$$

where complementary slackness applies to the last expression, and the superscript $*$ indicates the evaluation along the optimal path. The economic interpretation of the necessary conditions is deferred to a later section where we analyze the optimal trajectories of $s$ and $z$ together with the different qualitative properties of the social net return function.

\section{Pigouvian Taxes}

Based on Swiss data, Goetz and Zilberman showed that $\pi(g)$ is strictly convex and that it is optimal for the individual farmer to drain the land to the upper limit and to deplete the soil as fast as possible over the entire time horizon. In this paper we will not restrict ourselves to this particular example. More importantly, taking account of the social costs of the negative production externality in the form of groundwater or surface water pollution may alter the qualitative properties of the problem $(P)$. Even if $\pi(\beta z)$ is strictly convex in $z$, the function $\varphi(z)$ can either be convex or concave in $z$, depending on whether $\pi(\beta z)$ or $c(z)$ has the stronger curvature. To analyze the implications of these qualitative properties on the trajectories of $s^{*}$ and $z^{*}$, we will first discuss the case where $\varphi$ is convex, and thereafter where $\varphi$ is concave.

\section{The Social Net Return Function is Convex}

The qualitative properties of the optimal trajectories can be obtained by the following proposition.

Proposition 1. If the social net return function, given in problem $(P)$, is strictly convex in $z$, the optimal trajectory of $z$ is a boundary solution. $^{2}$

Proof. The idea is to reduce the convex problem to that of a linear one by the construction of a linear function $\hat{\varphi}$ whose graph lies above that of $\varphi$. This function is given by

\footnotetext{
${ }^{2}$ For the case where $\varphi$ is convex, the function can be partitioned such that $\varphi$ is strictly convex or linear on intervals of $z$. On these intervals, $\varphi$ can be analyzed in the same way as described in proposition 1 .
}

$$
\begin{aligned}
\hat{\varphi} & =\frac{[\pi(\beta a)-c(a)] b-[\pi(\beta b)-c(b)] a}{b-a} \\
& +\left\{\frac{\pi(\beta b)-c(b)-[\pi(\beta a)-c(a)]}{b-a}\right\} z .
\end{aligned}
$$

Note that $\varphi(a)=\hat{\varphi}(a)$ and $\varphi(b)=\hat{\varphi}(b)$; otherwise $\hat{\varphi}>\varphi$. Next, we will replace $\varphi$ in problem $(P)$ with $\hat{\varphi}$ and denote this problem by $(\hat{P})$. The linearity of $(\hat{P})$ in $z$ suggests the definition of a switching function, $\sigma$, given by

$$
\text { (9) } \begin{aligned}
& \sigma(t)=\hat{H}_{z} \\
= & \frac{\pi(\beta b)-c(b)-[\pi(\beta a)-c(a)]}{b-a}-\lambda(f+\gamma) \beta .
\end{aligned}
$$

As is known from the theory of optimal control, maximizing $\hat{H}$ requires the following choices:

$$
z=\left(\begin{array}{cc}
b, & \sigma(t)>0 \\
z \in Z, & \sigma(t)=0 \\
a, & \sigma(t)<0
\end{array}\right)
$$

If a singular path, $\sigma=0$, occurs for some positive interval of time, then the optimal trajectory of $z$ can also lie in the interior of $Z$. Let us assume that a singular path exists. Hence, for some positive interval of time, $\dot{\sigma}=-\dot{\lambda}(f+\gamma) \beta$ $-\lambda \dot{f} \beta=0$ has to hold, which yields

$$
\frac{\dot{\lambda}}{\lambda}=-\frac{\dot{f}}{f+\gamma}
$$

Utilizing equation (4) for an interior value of $Z$ results in

$$
\dot{f}=-\delta(f+\gamma)
$$

The general solution of this differential equation is $f(t)=c_{1} e^{-\delta t}-\gamma$, where $c_{1}$ is a constant. However, substituting $f(t)$ in equation (2) shows that $\gamma$, the constant of mineralization, cancels out, changing the qualitative properties of expression (2). Thus, we can conclude that $c_{1} e^{\delta t}-$ $\gamma$ is not an admissible solution and no singular path for any $z$ in the interior of $Z$ exists. Hence $z^{*}$ takes on a boundary value.

So far, we obtained qualitative properties of $z^{*}$ for the problem $(\hat{P})$. However, since $\varphi$ of 
problem $(P)$ is strictly convex in $z$, the subsidence of peatland is linear in $z$, and the switching function $\sigma(t)$ associated with problem $(\hat{P})$ does not vanish over a time interval of positive length, theorem 3.3 of Feichtinger and Hartl can be employed. This theorem suggests that the replacement of $\varphi$ by $\hat{\varphi}$ in problem $(P)$ yields the same optimal values for $s^{*}, z^{*}, \lambda^{*}$, where $z^{*}$ is given by $0, a, b$, or $s / \beta$. More precisely, vate net return function. We know further that $\pi$ is monotonically increasing, and thus proposition 1 suggests that the optimal private trajectory of $z$ is chosen from the upper boundary of the set $Z .^{3}$ However, the convexity of $\varphi$ does not determine the sign of $\varphi^{\prime}$, which in turn leaves the determination of the optimal value of $z$ open. Let us first consider the case where $\varphi^{\prime}>0$

$$
z^{*}=\operatorname{argmax}\left\{\max \left[H(0, \lambda, t), H(a, \lambda, t), H(b, \lambda, t), H\left(\frac{s}{\beta}, \lambda, t\right)\right]\right\}
$$

where the variables $s$ and $\lambda$ of the right-hand side of equation (12) have to be evaluated for the given boundary value of $z$.

In other words, in the case of a strictly convex social net return function, with respect to agricultural production, it may be optimal to drain the land as deeply as possible or as shallow as possible, or not at all. If $t_{1}<T$ and none of the Hamiltonians evaluated at $H\left(a, \lambda, t_{1}\right)$, $H\left(b, \lambda, t_{1}\right), H\left[(s / \beta), \lambda, t_{1}\right]$ is zero, then the transversality condition (6) requires that we choose $z\left(t_{1}\right)=0$ at the terminal point of time. Thus, the peatland will be utilized for agricultural production as long as $H(a, \lambda, t), H(b, \lambda, t)$ and $H[(s / \beta) \lambda, t]$ are strictly positive. If this condition fails to be satisfied over time, the utilization of the peatland for agricultural purposes would be terminated and the groundwater level would be raised to the topsoil level. Similarly, if $t_{1}=T$ and $H\left(a, \lambda, t_{1}\right), H\left(b, \lambda, t_{1}\right)$, and $H\left[(s / \beta) \lambda, t_{1}\right]$ are strictly negative, then $z\left(t_{1}\right)=0$ also has to be chosen to satisfy equation (6). However, if $H(a, \lambda, t), H(b, \lambda, t)$, and $H[(s / \beta) \lambda$, $t] \geq 0$, for all $t$, then $z^{*}\left(t_{1}\right) \geq 0$. For this case, it may be optimal to leave the minimum layer of peat or even more in the ground.

Social versus private outcome for the convex case. Next, we will analyze the conditions for an optimal social outcome, which is distinct from an optimal private outcome, and requires a regulator to correct the market outcome. Note that the case of a convex social net return function implies that the private net return function, $\pi$, is also convex. Otherwise, the social net return function as a sum of two concave functions, $\pi(\beta z)$ and $-c(z)$, would also be concave. Moreover, the convexity of $\varphi$ also requires that $\varphi^{\prime \prime} \geq c^{\prime \prime}$. The case of a linear social cost function, for example, would give rise to a convex social net return function, given a convex pri- for $\varphi>0$, and the socially and privately optimal trajectories are identically given by an upper boundary value of $Z$. In this case, there is no need to correct the market outcome because it is also optimal from the social point of view. However, if $\varphi^{\prime}=\pi^{\prime}-c^{\prime}<0$ for $\varphi>0$, say for $t>\hat{t}$, then the privately and socially optimal outcomes are distinct, and the market outcome needs to be corrected such that the farmer chooses $a$. For the case $\varphi<0$, it would be socially optimal not to drain the land at all. Thus, a tax

$$
\tau(t)=\left\{\begin{array}{cc}
0 ; & t \leq \hat{t} \\
c\left(z_{p}^{*}\right) ; & t>\hat{t}
\end{array}\right\}
$$

would induce the optimal social outcome where $z_{p}^{*}$ refers to the optimal private outcome. Hence, at point $\hat{t}$ the farmer would either switch to $z=a$ or to $z=0$. However, regardless of the optimal social outcome beyond time $\hat{t}$. the farmer may choose not to develop the land at all since the investment in the drainage system may no longer be profitable when $\tau$ is incorporated in a cost benefit analysis.

For the calculation of the $\operatorname{tax} \tau$ the function $c(z)$ needs to be known over the interval $[a, b]$. When this function is not available, an upper bound to social costs can be obtained provided that information exists supporting the convexity

\footnotetext{
${ }^{3}$ This result can be obtained even though proposition 1 requires strict convexity. As indicated in footnote 2 an appropriate partition of the private net return function enables us to apply proposition 1 for the different segments of the partition. In the case where the segment is strictly convex, proposition 1 can be applied directly. If the segment is linear, then a boundary solution also can be established by the fact that the switching function does not vanish over a positive interval of time.
} 
of the function over the interval $[a, b]$, and the points $c(a)$ and $c(b)$ are known. A linearization of $c(z)$, denoted by $v(z)$, is given by

$$
v(z)=\frac{c(a) b-c(b) a}{b-a}+\left(\frac{c(b)-c(a)}{b-a}\right) z
$$

where $v(z)>c(z)$ for $z \in(a, b)$, and $v(a)=c(a)$ and $v(b)=c(b)$. Replacing $c(z)$ with $v(z)$ in problem $(P)$ and solving for the optimal trajectory of $z$ yields a boundary solution. If the consideration of the negative production externality has no effect on the optimal private outcome, no Pigouvian tax needs to be imposed. Hence, the upper bound of the social cost serves as a benchmark to decide whether or not the market outcome needs to be corrected at all.

\section{The Social Net Return Function is Concave}

In contrast to the previous section we look now at optimal solutions lying in the interior or at the boundary of $Z$. The transversality condition (7) for the case of an interior solution shows that $\lambda\left(t_{1}\right)=0$, given $s\left(t_{1}\right)-\beta a>0$. Next, solving equation (4) yields $\lambda(t)=A_{1} e^{-\delta t}$, where $A_{1} \geq 0$ is determined by the condition $\lambda\left(t_{1}\right)=0$. However, this implies that $\lambda(t)=0$, contradicting the dynamic properties of problem $(P)$. Hence, we can conclude that an interior solution over the entire time interval $\left[t_{0}, t_{1}\right]$ is not possible because the requirement $s\left(t_{1}\right)=\beta a=\beta z^{*}\left(t_{1}\right)$ cannot be satisfied. At least at the terminal point in time, $z$ takes on a boundary value.

Social versus private outcome for the concave case. In order to compare the social outcome with the private outcome we need to define some qualitative properties of $\pi$. Let us assume for now that $\pi$, besides $\varphi$, is concave. For an interior solution, the optimal private strategy $z_{p}^{*}$ differs from that of the optimal social strategy $z_{s}^{*}$ as can be seen from the necessary conditions for an interior solution of the private and social problem, given respectively by

$$
\begin{aligned}
& \pi^{\prime}(\beta z) \beta=\lambda(f+\gamma) \beta \\
& \pi^{\prime}(\beta z) \beta-c^{\prime}(z)=\lambda(f+\gamma) \beta
\end{aligned}
$$

Moreover, we know that every optimal solution that starts as an interior solution will turn into a boundary solution after some time. Because of negligence of the social costs, the optimal private strategy reaches the boundary before the optimal social strategy. ${ }^{4}$

To analyze the possibilities for a regulator to correct the market outcome, we introduce an ad valorem $\operatorname{tax} \tau$. Thus, the necessary condition for the solution of the farmer's problem yields

$$
\begin{array}{r}
(1-\tau) \pi^{\prime}(\beta z) \beta-\lambda(f+\gamma) \beta-\phi_{3} \beta=0 \\
\Rightarrow \tau(z)=1-\frac{\lambda(f+\gamma)+\phi_{3}}{\pi^{\prime}(\beta z)}
\end{array}
$$

where we consider the example of a boundary solution for $s(t)=\beta z$. If the regulator sets the tax equal to $\tau\left(z_{s}^{*}\right)$, then $z_{s}^{*}$, the solution to the necessary condition of the social problem given in equation (16), also solves the necessary condition of the private problem, given in equation (17). In other words, the individual farmer chooses the groundwater level which is identical with the socially optimal groundwater level. In this way, the optimal private and social strategies will reach the boundary at the same time, and no tax is required for the time thereafter.

If $\pi$, however, is convex, any linear $\operatorname{tax} \tau$ on the private net return will not alter the curvature of $\pi$, and the private outcome is always given by a boundary solution. To obtain a private strategy which lies in the interior of $Z$ and is identical with the social strategy, a nonlinear tax on private net returns is required. We propose three different tax schemes, where the first one, in the form of a step function, is the limiting case of the second one. Consider the following tax:

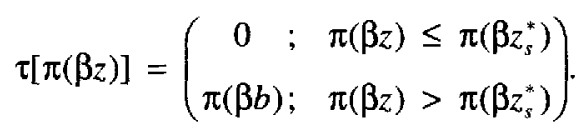

For any upper deviation from the socially optimal water pollution level the tax is prohibitive, but it is equal to zero for any lower deviation from the optimal social strategy. While this tax is easy to administer, it is most likely not politically feasible since it basically places a cap on the farmer's net returns. A tax which is continuously increasing but starting out low for small upper deviations may be politically easier to introduce. For the derivation of this tax, mathematically expressed as $\tau[\pi(\beta z)]$, consider first

\footnotetext{
${ }^{4}$ The proof can be obtained from the author upon request.
} 
the necessary condition for an interior solution of the private problem given by

$$
\begin{array}{r}
\left\{1-\tau^{\prime}[\pi(\beta z)]\right\} \pi^{\prime}(\beta z) \beta-\lambda(f+\gamma) \beta=0 \\
\Rightarrow \tau^{\prime}[\pi(\beta z)]=1-\frac{\lambda(f+\gamma)}{\pi^{\prime}(\beta z)}
\end{array}
$$

Equation (19) has to hold at $z=z_{s}^{*}$. The secondorder condition, which has to hold for any $z>z_{s}^{*}$, implies

$$
\tau^{\prime \prime}[\pi(\beta z)]>\left[\pi^{\prime \prime}(\beta z)\right] \frac{\lambda(f+\gamma)}{\left[\pi^{\prime}(\beta z)\right]^{3}}
$$

where equation (19) was utilized. One candidate for the tax, satisfying equations (19) and (20), is given by

$$
\tau[\pi(\beta z)]=\left\{\begin{array}{c}
0 \\
\frac{1}{2}[\pi(\beta z)]^{2}-\lambda(f+\gamma) \beta z+\frac{z^{3}}{3\left(z_{s}^{*}\right)^{2}}-\frac{z^{2}}{2\left(z_{s}^{*}\right)} ; \quad \pi(\beta z)>\pi\left(\beta z_{s}^{*}\right)
\end{array}\right\} .
$$

The tax scheme in equation (21) induces the net-return-maximizing farmer to choose $z_{s}^{*}$.

The first two taxes, as proposed in equations (18) and (21), are not directly related to the monetary damage from the water pollution. Thus, they can be seen as a method to implement a certain standard. The third proposed possibility for the regulator to correct the market outcome is to employ the social costs $c(z)$ as a tax scheme. Because this tax scheme reflects the monetary damages accurately, it seems to be superior to the first two tax schemes. However, the implementation of this tax would require information about $z$, which may not be easily observable. Instead of $z$ it would be easier to observe the farmer's net returns. Hence, we consider the invertible function $y=\pi(\beta z)$. The tax can now be expressed as a function of the farmer's net returns and is given by

$$
\tau[\pi(\beta z)]=c\left[\frac{\pi^{-1}(y)}{\beta}\right]
$$

Faced with this tax, the net-return-maximizing farmer chooses $z_{s}^{*}$ that is identical to that given by the solution to the necessary conditions for an interior solution for the private and social problems.

\section{Summary}

Initial or repeated land development for agricultural production results in groundwater and surface water pollution in the case of peatland. As shown in the literature, the farmer's net return function may not be concave since farmers switch to the production of more valuable crops as more soil becomes available. Thus, taking account of the additional costs from the water pollution may result in a convex or concave social net return function. In the case where the social net return function is convex, the privately and socially optimal outcomes may be identical and no market correction is required. However, if the two outcomes are distinct, a Pigouvian tax is proposed which leads to a less intensive use of the land or to the decision not to develop the land at all. Even if the optimal social outcome suggests the extensive use of the land, the farmer may decide not to use the land at all because investing in the drainage system is no longer profitable due to the imposition of a Pigouvian tax.

The case where the private as well as the social net return function are concave results in a linear Pigouvian tax on the private net return function. However, if the social net return function is concave while the private net return function is convex, a linear Pigouvian tax on the private net return function does not exist which corrects the market outcome such that the socially optimal outcome, given by an interior solution, is chosen by the farmer. To accomplish this objective, three different tax schemes are proposed, where the tax is a nonlinear function on the private net returns.

[Received June 1995; final revision received January 1997.]

\section{References}

Barnett, A. "The Pigouvian Tax Rule Under Monopoly." Amer. Econ. Rev. 70(December 1980):1037-41. 
Baumol, W., and D. Bradford. "Detrimental Externalities and Non-convexity of the Production Set." Economica 39(May 1972):160-76.

Baumol, W., and Oates, W. The Theory of Environmental Policy, 2nd ed. Cambridge: Cambridge University Press, 1988.

Briemle, G. "Natürliche Bewaldungstendenz und Mindestpflege von Moorbiotopen." Moor- und Torfkunde, 3rd ed. K. Göttlich, ed., chap. 5.5. Stuttgart: E. Schweizerbart'sche, 1990.

Cropper, M., and W. Oates. "Environmental Economics: A Survey." J. Econ. Lit. 30(June 1992):675-740.

Feichtinger, G., and R. Hartl. Optimale Kontrolle Ökonomischer Prozesse. Berlin: Walter de Gruyter, 1986.

Goetz, R., and D. Zilberman. "Mining the Soil-Agricultural Production Systems on Peatland." Environ. and Resour. Econ. 6(September 1995):119-38.

Göttlich, K., and H. Kuntze. "Natürliche Bewaldungstendenz und Mindestpflege von Moorbiotopen." Moor- und Torfkunde, 3rd ed., K. Göttlich, ed., chap. 5.1. Stuttgart: E. Schweizerbart'sche, 1990.

Guthrie, T., and J. Duxburg. "Nitrogen Mineralization and Denitrification in Organic Soils." Soil Sci. Amer. J. 42(November/December 1978):908-12.

Kuntze, $\mathbf{H}$. The Risks of Water Pollution by Agricultural Utilization of Peatlands and Practical Defense. Proceedings of the 7th International Peat Congress, International Peat Society, Dublin, Ireland: 18-23 June 1984, pp. 246-67.

Kuntze, H., G. Roeschmann, and G. Schwerdtfeger.
Bodenkunde, 4th ed. Stuttgart: Eugen Ulmer, 1988

Lee, D. "Efficiency of Pollution Taxation and Market Structure." J. Environ. Econ. and Manage. 2(September 1975):69-72.

Maslov, B., and E. Panov. Peat Soils: Improvement and Agricultural Use in the USSR. Proceedings of the 6th International Peat Congress, International Peat Society, Duluth MN, 17-23 August 1980, pp. 421-25.

Pearce, D. Environmental Economics. London: Longman, 1976.

Pfadenhauer, J., H. Schneekloth, S. Schneider, and R. Schneider. "Stellung der Moore im Raum." Moor- und Torfkunde, 3rd ed. K. Göttlich, ed., chap. 2. Stuttgart: E. Schweizerbart'sche, 1990.

Poirée, M., and C. Ollier. Assainissement Agricole. Paris: Eyrolles, 1978.

Schothorst, C. "Subsidence of Low Moor Peat Soils in the Western Netherlands." Geoderma. 17(April 1977):265-91.

Segeberg, H. "Moorsackungen durch Grundwasserabsenkungen und deren Vorausberechnung mit Hilfe empirischer Formeln." Zeitschrift pür Kulturtechnik und Flurbereinigung. 1(January/ February 1960):144-61.

Spulber, D. "Effluent Regulation and Long-run Optimality." J. Environ. Econ. and Manage. 12(June 1985):103-16.

Starrett, D. "Fundamental Nonconvexities in the Theory of Externalities." J. Econ. Theory. 4(April 1972):180-92.

Takayama, A. Mathematical Economics, 2nd ed. Cambridge: Cambridge University Press, 1985. 